\title{
Contribution to Fire Resistance from Building Panels
}

\author{
B. J. NORÉN AND B. A.-L. ÖSTMAN
}

Swedish Institute for Wood Technology Research

Box 5609, S-114 86 Stockholm, Sweden

\section{ABSTRACT}

The contribution from different types of building panels to the total fire resistance of a construction has been determined experimentally by testing in furnaces of three different sizes. The agreement between a full size furnace according to ISO 834 and a small size furnace is good, while a medium size furnace gives a somewhat higher fire resistance.

The panel thickness is the most important factor and has an almost linear relationship with the fire resistance, common for all wood-based boards and also including gypsum boards. Other factors as panel density, moisture content, type of adhesive and structural composition of the panel will also affect the contribution to the fire resistance. The behavior of various wood -based panels may therefore be slightly different. The fire penetration rate as determined from the measurements in a furnace exposure according to ISO 834 is slower than $0.9 \mathrm{~mm} / \mathrm{min}$ for all boards with density over $400 \mathrm{~kg} / \mathrm{m}^{3}$.

The insulation criterion is usually determining the fire resistance, while the panel integrity remains a little longer. This is especially true for inorganic boards which may have a considerably longer time until the integrity criterion fails, while the insulation criterion gives a fire resistance of the same order of magnitude as wood-based boards.

The influence of some design factors as mineral insulation, studs and double layers of panelling has also been studied, as well as varying thermal exposure.

\section{INTRODUCTION}

The fire resistance of elements of building constructions is usually determined by the internationa11y accepted test method Iso 834, which tests in full scale, e.g. wall elements of $3 \times 3 \mathrm{~m}$. The test elements form part of a furnace, in which the temperature increase follows a standard time-temperature curve, reaching e.g. $659^{\circ} \mathrm{C}$ after 10 minutes, $821^{\circ} \mathrm{C}$ after 30 minutes and $925^{\circ} \mathrm{C}$ after 60 minutes. The elements may be load-bearing or not load-bearing during the test depending on the application. The following three criteria are used:

- load-bearing capacity (withdrawn for non load-bearing elements),

- insulation, $i . e$. the temperature increase of the unexposed face shall be below an average of $140{ }^{\circ} \mathrm{C}$ and a maximum of $180^{\circ} \mathrm{C}$, 
- integrity, i.e. the test element shall not crack or release flames.

The time in minutes until one of these criteria fails is by definition the fire resistance of the element.

Such a full scale testing is expensive. Smaller furnaces have been developed which might give useful information, especially for non load-bearing constructions, but they need verification with full scale in most cases. The design of these smaller furnaces may vary and they have not been standardized. Just a German proposal exists (DIN 4102).

The fire resistance can also be determined by theoretical calculations, but methods and basic data are still lacking for wooden constructions. A review (Pettersson and Jönsson) and a research program for developing analytical methods (Jönsson and Pettersson) have recently been presented.

A more simple approach for some types of constructions is to determine the contribution from different components to the total fire resistance of the construction. Such an approach has been proposed and plain applications have shown good agreement with full scale testing of the whole construction in spite of great simplifications (Hagstedt and Nyström; Dansk Brandværnskomité).

Building panels are components with great importance for the fire resistance. Relatively few studies have been published on the contribution from different types of panel. A recent review (óstman) shows that the contribution from panels is considered to be quite different in different studies. The main reason is differences in test methods and criteria. A suitable test for the contribution from panels shall be in accordance with the criteria for the fire resistance of the whole construction. The requirements for separating, non load-bearing construction are therefore applicable, i.e. insulation and integrity as mentioned above. This has been applied in a study carried out at the Swedish Institute for Wood Technology Research and summerized here. A full report is also available (Norén and östman).

The aim is to determine the contribution from different building panels to the total fire resistance of a construction. The results might be useful for the fire classification of walls mainly. A large number of panels have been studied, most of them are wood-based, but different inorganic panels have also been included. Factors as panel thickness, density, type of adhesive have been studied, as well as the influence of design factors as mineral insulation, studs and double panel layers.

\section{EXPERIMENTAL}

Three furnaces of different sizes have been used, two in reduced scale and one in full scale. All furnaces have followed the standard time-temperature curve according to ISO 834. Some identical constructions have been tested in all furnaces to verify the agreement. Then most of the tests have been carried out in the small furnace.

The smal1 furnace consists of a steel box with a side length of approximately $0.6 \mathrm{~m}$. It has an inside, $70 \mathrm{~mm}$ thick ceramic insulation with density about $850 \mathrm{~kg} / \mathrm{m}^{3}$. It is heated by a gas burner which is operated manually and the standard fire curve is obtained within narrow limits. It may be operated with vertical or horizontal test elements. The size of these elements is $0.5 \times 0.6 \mathrm{~m}$. 
The medium size furnace is walled with the same insulating brick as the small furnace, but heated with an oil burner. It has two openings, one vertical $1.24 \times 1.23 \mathrm{~m}$ and also one horizontal, which was not used in these experiments. The size of vertical test elements is $1.7 \times 1.6 \mathrm{~m}$.

The large furnace is a conventional vertical furnace heated with oil burners. The size of the test elements is $2.4 \times 3 \mathrm{~m}$.

The test panels were different wood-based boards, i.e. particle boards, hardboards and plywood, with thicknesses between 3 and $30 \mathrm{~mm}$. Some common inorganic boards were also evalutated, e.g. gypsum boards, cement bonded boards and boards made of calcium silicate. All boards were taken from commercial production, but chosen so that the influence of factors as thickness, density and adhesive could be studied systematically.

Composits were made with wood studs, $45 \times 95 \mathrm{~mm}$, and in some cases insulated with mineral wool with a density of $30 \mathrm{~kg} / \mathrm{m}^{3}$.

All test elements were stored to moisture equilibrium at $50 \% \mathrm{r} . \mathrm{h}$. and $23{ }^{\circ} \mathrm{C}$ before testing. Four elements were tested in the large furnace, five in the medium size furnace and about 50 different elements evaluated in duplicate tests in the small furnace. Most elements were oriented vertically, i.e. in wa11 position.

Thermocouples were applied on many places, mainly on the unexposed face of the panels, but also between panels, between panel and insulation and at studs. The signals from all thermocouples were stored on discs and then evaluated. Visual observations were also noted, especially cracking or other integrity failure.

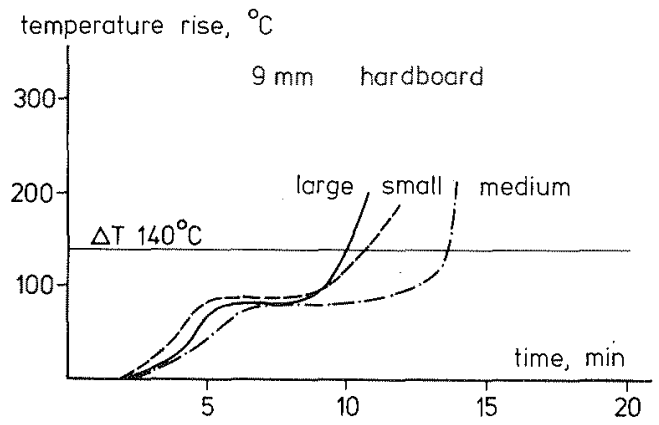

FIGURE 1 .

Comparison of three different furnace sizes. Time-temperature curves for $9 \mathrm{~mm}$ hardboard of density $800 \mathrm{~kg} / \mathrm{m}^{3}$ with $\mathrm{mi}-$ neral wool insulation. 


\section{DIFFERENT FURNACES AND TEST CONDITIONS}

Figure 1 compares the fire resistance determined in the three furnaces of different size. The test element is a wall consisting of a $9 \mathrm{~mm}$ hardboard on wood studs and insulated with mineral wool. The contribution from the hardboard panel as given in the figure is almost the same, within less than one minute, for the small and the large furnaces, while the medium size furnace gives a longer contribution. This is probably mainly due to differencies in time constants for the thermocouples controlling the funnace temperature. The same tendency was found also for other wall constructions.

The fire resistance was generally determined by the criterion of insulation with a few exceptions especially for very thin panels. The limit for the average temperature was usually reached at first, then the maximum temperature and somewhat later the panel cracked i.e. integrity failure. The repeatability when testing an identical element in the same furnace was good for a11 three furnaces and in the order of 0.6 minutes for the large furnace, 1.0 minutes for the medium size furnace and 0.5 minutes for the small furnace when testing a $10 \mathrm{~mm}$ thick panel.

The thermal exposure was varied during some experiments in the small furnace. Figure 2 shows that lower thermal exposure than the standard fire curve seems to give a better fire resistance, while a slightly higher thermal exposure seems to have little effect. However, higher thermal exposure than near the upper tolerance limit was hard to reach. But it still seems to be important not to have too low thermal exposure in order to get reproducable results. A slightly higher temperature than the standard fire curve seems to have less inf1uence.

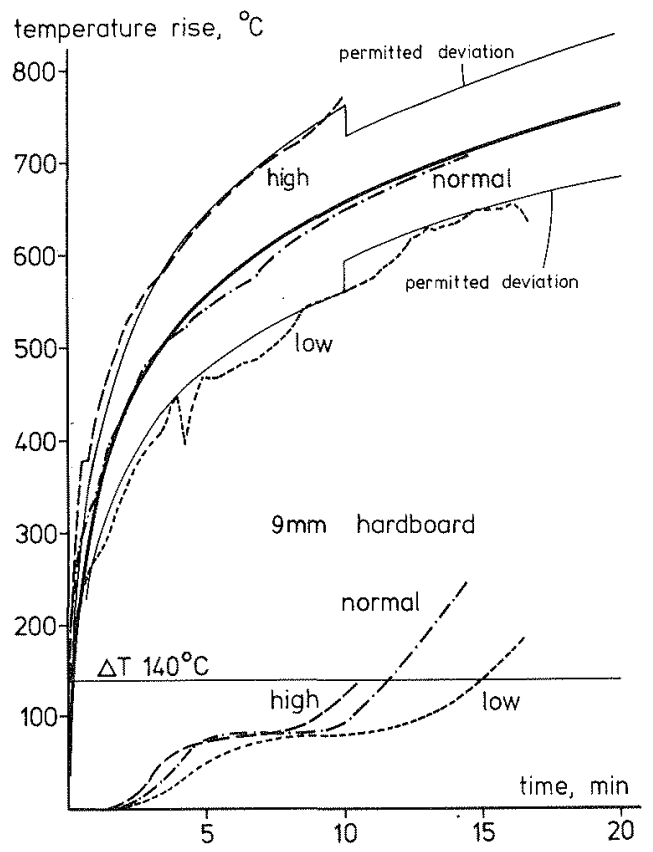

FIGURE 2 .

Furnace temperatures and timetemperature curves for $9 \mathrm{~mm}$ hardboard of density $800 \mathrm{~kg} / \mathrm{m}^{3}$ at different thermal exposures. 
INFLUENCE OF SOME COMMON PANEL PROPERTIES

The influence of some common panel properties as thickness, density and moisture content is summarized below. All data are for uninsulated panels. The influence of insulation and studs is given separately.

\section{Thickness}

The panel thickness is the most important factor for determining the contribution to the fire resistance. The relationship between fire resistance and thickness is not exactly linear, but is better given by a parable through origo:

$b_{m}=1.128 t+0.0088 t^{2}$

where $b_{\mathrm{m}}$ is the contribution to fire resistance (in minutes). $t$ is the panel thickness (in $\mathrm{mm}$ ).

The parable shape is probable because thicker boards get a thicker protective char layer which means slower fire penetration and higher fire resistance.

Different types of wood-based panels might have slightly different fire resistance at equal thickness, see figure 3 , which gives experimental data with indications of panel types. The differences in fire resistance at equal thickness depend on different densities, structures and adhesives. Panels with high density tend e.g. to have higher fire resistance.

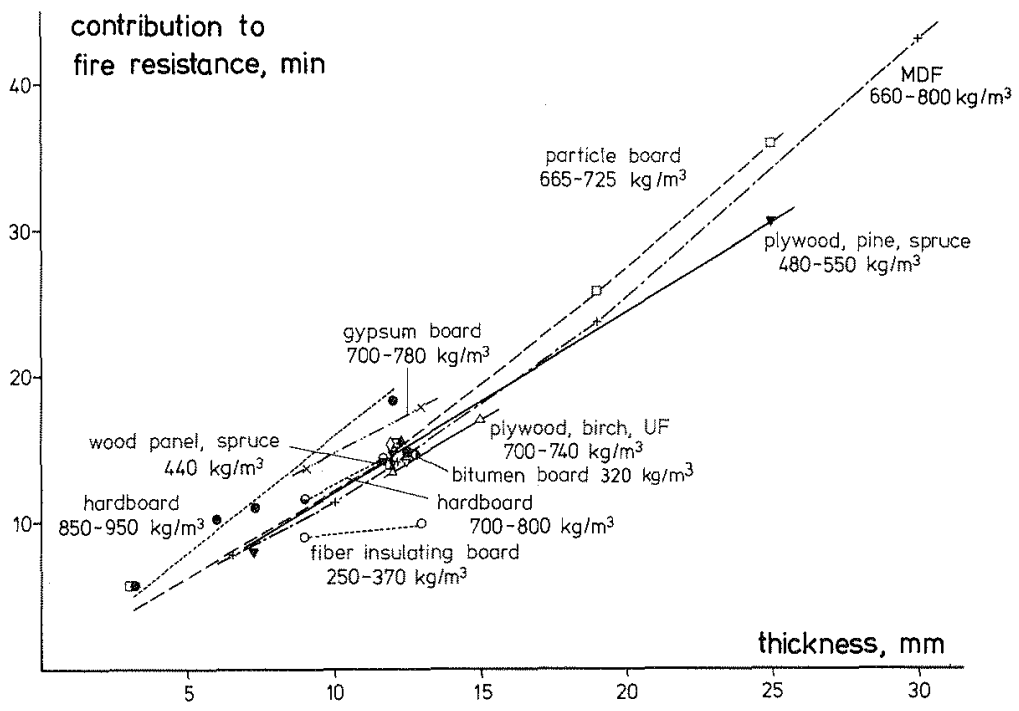

FIGURE 3. Effect of panel thickness on the contribution to fire resistance with specification of different wood-based boards and including gypsum boards. 
However, some panels with low density seem to have an unexpected high fire resistance, e.g. bitumen board which has higher fire resistance than ordinary insulating board at equal density and thickness. One reason is that insulating board cracks before the temperature criterion is reached, while the fire resistance for most other boards in figure 3, including bitumen board, is determined by the temperature criterion.

On the other hand, some panels with high density have an unexpected low fire resistance. One example is plywood made of birch and glued with urea resin which has low thermal stability and causes splitting of the plys.

Gypsum boards are also included in figure 3. They have only slightly higher fire reistance than most wood-based boards and about the same resistance as high density wood-based boards. The temperature criterion determines the fire resistance for gypsum boards as for most wood-based boards except insulating boards and very thin boards.

\section{Density}

The density has less influence than the thickness on the contribution to fire resistance. Figure 4 shows that three times higher density causes just twice the fire resistance or less. Fiber building boards which are manufactured at widely different densities were used for these experiments.

Higher density means higher thermal conductivity. For inorganic panels with high density this often also means that the temperature criterion determines its contribution to the fire resistance, sometimes much earlier than the integrity fails. But there are some exceptions e.g. some cement-bonded boards which crack early and before the temperature criterion is reached.

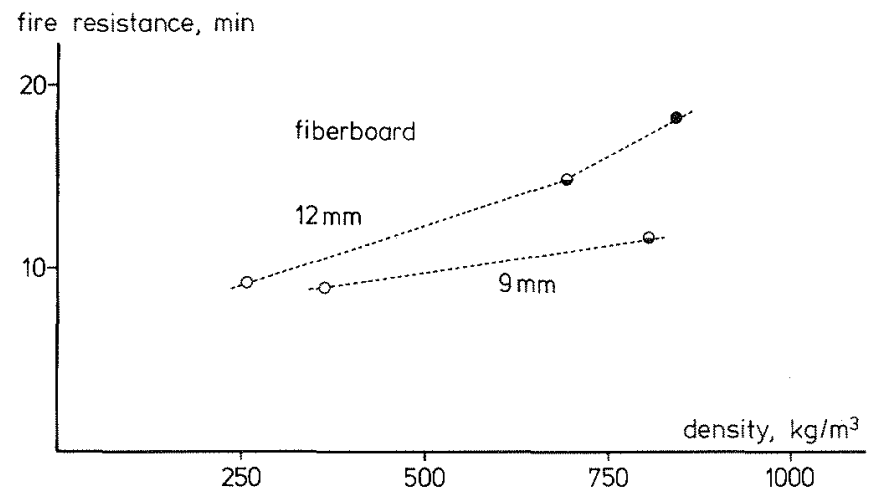

FIGURE 4.

Influence of panel density on contribution to fire resistance for woodbased fiberboards. 


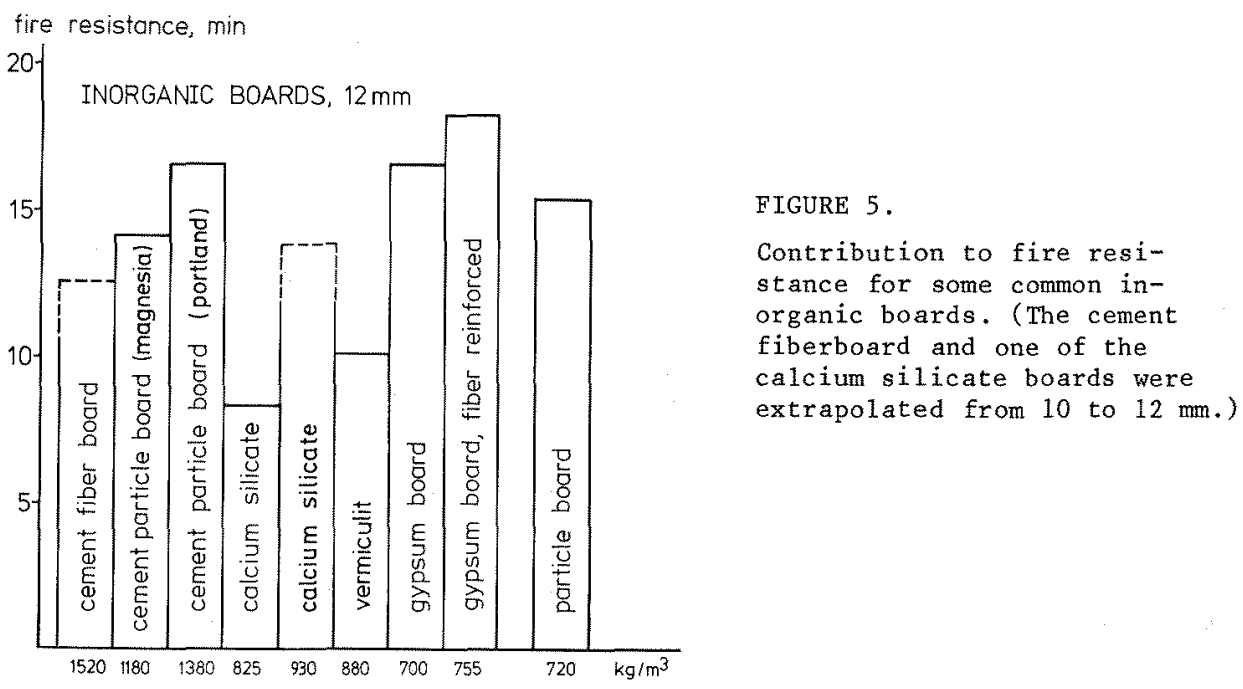

The fire resistance for some inorganic panels is given in figure 5 . A fiberreinforced gypsum board has the highest fire resistance followed by an ordinary gypsum board and a cement-bonded particle board, which has only 1 to 2 minutes longer time than ordinary particle board. Some inorganic panels have lower fire resistance, probably due to a low equilibrium moisture content.

\section{Moisture content}

A11. panels were in moisture equilibrium at $50 \% \mathrm{r} . \mathrm{h}$. and $23^{\circ} \mathrm{C}$ before testing except in a few cases when the influence of moisture content was studied. Some panels were then either dried or given higher moisture content. The effect on fire resistance is given in figure 6 , which shows a linear relationship with an increase of $0.4 \mathrm{~min} / \%$, i.e. $25 \mathrm{~s} / \%$.

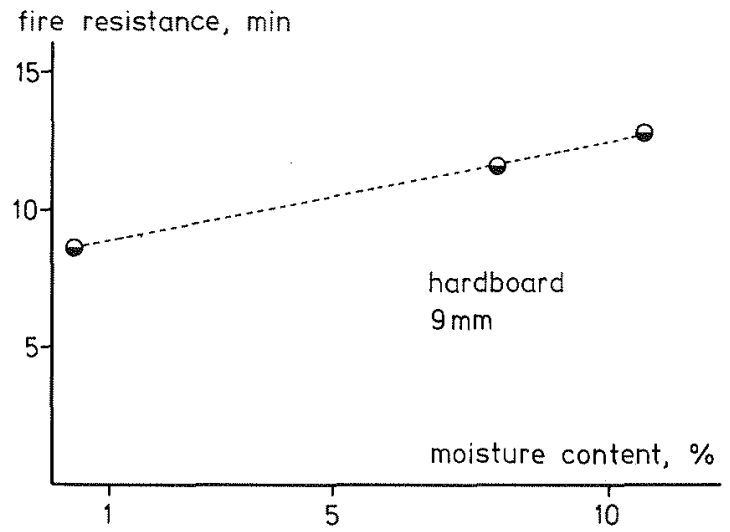

FIGURE 6.

Relationship between contribution to fire resistance and moisture content for $9 \mathrm{~mm}$ hardboard of density $800 \mathrm{~kg} / \mathrm{m}^{3}$. 
Fire penetration rate

The rate of fire penetration through panels is given in figure 7 as a function of panel density.

This rate, here called the fire penetration rate, is not identical with the charring rate, as used for solid wood, since it is based on a temperature criterion and not on charring. But these two rates are certainly related, and the charring rate is probably somewhat lower, as the panels are usually not charred on the unexposed face when the temperature criterion is reached. The fire penetration rate is, in spite of this, not much higher, $0.7-0.9 \mathrm{~mm} / \mathrm{min}$, than the charring rate usually applied for solid wood, $0.6-0.8 \mathrm{~mm} / \mathrm{min}$. The only panel with a fire penetration rate higher than $0.9 \mathrm{~mm} / \mathrm{min}$ is insulating board with very low density.

The fire penetration rate may have a larger scatter with time than the charring rate usually determined for solid wood. There are two reasons for this. One reason is that the charring rate is constant only when a certain part of undestroyed wood remains, while the fire penetration rate is determined over the total panel thickness. The other reason is that most panels don't have an equal density over the thickness, but a gradient with higher density near the surfaces and lower density in the core.

But still the fire penetration rate seems to supply some useful information about the contribution to fire resistance from different panels.

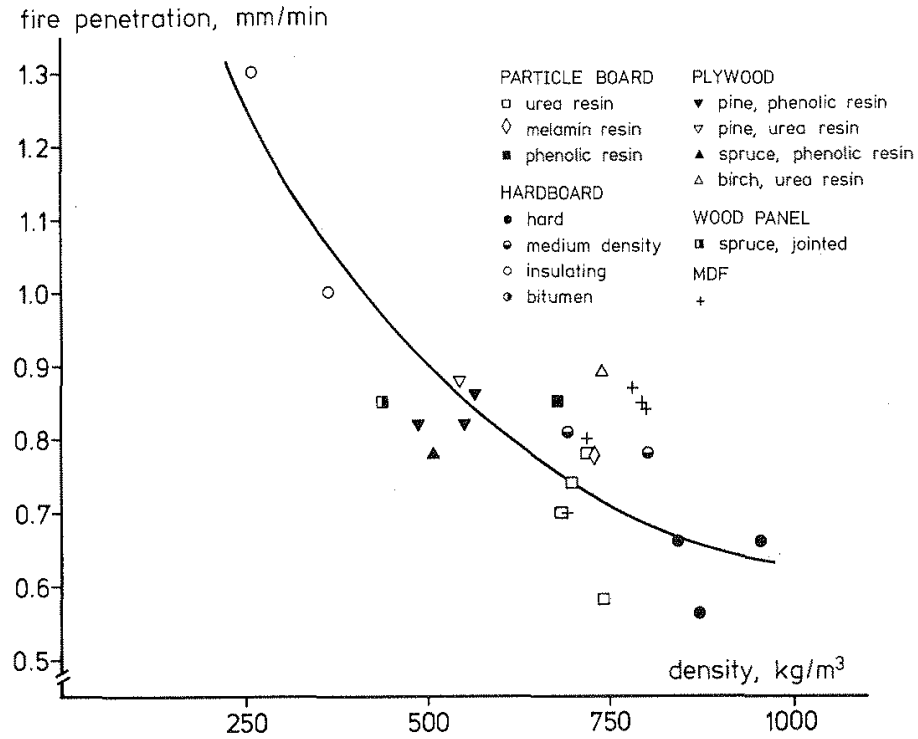

FIGURE 7. Fire penetration rate for wood-based panels as a function of density. 


\section{DESIGN FACTORS IN CONSTRUCTIONS}

The contribution to fire resistance from building panels is besides different internal properties also depending on how they are used, $i . e$. on design factors in constructions as insulation, studs and double panel layers.

Insulation of a wall with mineral wool will slightly decrease the contribution of a panel to the fire resistance. Figure 8 gives some data for hardboard and gypsum board of equal thickness. This effect is easy to understand since the insulation will increase the temperature on the unexposed face of the panel. The panel will then dry quicker and its fire resistance will decrease. The difference in fire resistance between an insulated and an uninsulated panel seems to be slightly less for a hardboard than for a gypsum board.

Studs will also decrease the fire resistance of a panel, i.e. the contribution from a panel is less at studs than between studs, see figure 9. If the pane1 is jointed, the fire resistance is further decreased, because the panel shrinks when it is exposed to fire and the joint is enlarged. The fire can then penetrate much easier.

Double pane1 layers will decrease the fire reistance of the first exposed pane1 only slightly when compared to a single pane1 layer. The second panel then acts as insulation. This is true for both hardboard and gypsum board, but the effect is less than for insulation of mineral wool and for studs.

The total contribution of a double panel layer to the fire resistance is about twice the contribution of a single layer of hardboard and about three times the contribution of a single layer of gypsum board.

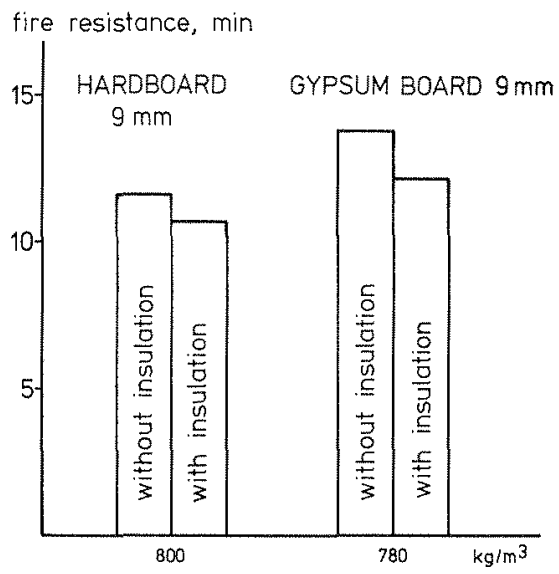

FIGURE 8 .

Effect of insulation. Hardboard and gypsum board with $95 \mathrm{~mm}$ mineral wool insulation.

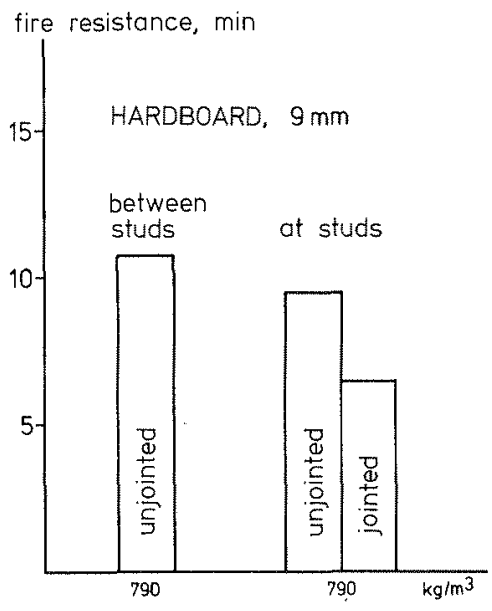

FIGURE 9 .

Contribution to fire reistance at studs and between studs. The panel at studs is jointed or unjointed. 


\section{CONCLUSIONS}

The contribution to the fire resistance from building panels can be evaluated in a small scale furnace operating according to the standard time-temperature curve in ISO 834 . The contribution is equal to that evaluated in a full scale furnace.

A thermal exposure slightly higher than the standard time-temperature curve seems to have less effect on the fire resistance than a lower thermal exposure.

The panel thickness is the most important factor for determining the contribution to the fire resistance. Other factors are panel density, moisture content, type of adhesive and structural composition of the panel.

Inorganic panels as gypsum boards have only slightly larger contribution to the fire resistance than wood-based boards.

The insulation criterion is determining the fire resistance in most cases while the panel integrity remains a little longer, especially for some inorganic boards as high density mineral fiber boards.

Design factors in wall constructions as mineral wool insulation and studs will slightly decrease the contribution to the fire resistance from building panels.

The data presented here are mainly applicable when evaluating the fire resistance of timber framed wall constructions. They may also form a basis for a more theoretical approach. 


\section{REFERENCES}

Dansk Brandverns-komité:

Beregningsmasig bestemmelse av lette, ikke bærende pladebekladte

traskeletvegges brandmotstandsevne.

Reports Dec. 1980 and Aug. 1982 (in Danish).

Deutsche Normen:

Brandverhalten von Baustoffen und Bauteilen. Kleingrifstand.

DIN 4102, Teil 8 Entwurf, 1977.

Forest Products Laboratory:

Fire resistance tests of plywood-covered wall panels.

USDA For. Serv. Rep. No. 1257, 1956.

Hagstedt, J. and Nyström, P.:

Skiljande träkonstruktioner.

Statens råd för byggnadsforskning, Stockholm.

Report R 91:1977 (in Swedish).

Jönsson, R. and Pettersson, 0. :

Träkonstruktioner och brand. Kunskapsöversikt och forskningsbehov.

Byggnadstekniskt brandskydd.

Tekniska högskolan i Lund. Report LUTVDG/(TVBB-3015), 1983.

(In Swedish.)

Kordina, K. and Meyer-Ottens, C.:

Ho $1 z-$ Brandschut $z-H a n d b u c h$.

Deutsche Gesellschaft für Holzforschung e.V. München, 1983.

Meyer-ottens, C.:

Behaviour of loadbearing and non-loadbearing internal and external walls of wood-based materials under fire conditions.

Proc. Symposium No. 3 on Fire and structural use of timber in buildings. Joint

Fire Res. Org. HMSO London, 1967.

Norén, J. and östman, B.A-L.:

Skivmaterials bidrag till brandmotståndet.

Swedish Institute for Wood Technology Research. Report No. 79, 1985.

(In Swedish.)

Pettersson, 0 . and Jönsson, R.:

Fire design of wooden structures.

Internatinal Seminar on three decades of structural fire safety, Fire Research Station, UK Febr. 1983.

White, R.H.:

Wood-based paneling as thermal barriers.

USDA For. Serv. Res. Pap. FPL 408, 1982.

Östman, B.A-L.:

Fire penetration rate in different building boards. Critical 1iterature

review.

Proceedings. New available techniques. The world pulp and paper week.

Stockholm, April 10-13, 1984. 
